\title{
The effect of clothing fit and material of women's Islamic sportswear on physiological and subjective responses during exercise in warm and humid environment
}

\author{
Astrid Wahyu Adventri Wibowo*, Titis Wijayanto*, Watri Widyastuti, and Muhammad Kusumawan Herliansyah \\ Gadjah Mada University, Departement of Mechanical and Industrial Engineering, Jl. Grafika 2, Yogyakarta, Indonesia
}

\begin{abstract}
The purpose of this study was to investigate the effects of clothing fit and material of Islamic sportswear for female on physiological responses and body heat balance during exercise in warm and humid environment. Twelve healthy female students $(20.3 \pm 0.4$ years $)$ exercised wearing four types of women's Islamic sportswear comprised of two level of clothing fit: loose-fit and tight-fit, and two types of material for sportswear: cotton and polyester on four separate occasions, and in random order. They performed a 30-min treadmill exercise at an intensity of $70 \% \mathrm{HR}_{\max }$ and then rested on a chair for $20 \mathrm{~min}$ for recovery in a chamber set at an ambient temperature of $34^{\circ} \mathrm{C}$ and relative humidity of $80 \%$. The results showed that clothing fit did not significantly affect physiological and subjective responses, but clothing material did; sportswear made of cotton resulted in a higher increase of tympanic temperature during exercise and recovery compared to that made of polyester $(\mathrm{P}<0.05)$. In addition, sportswear made of cotton have lower conductive and evaporative heat loss than sportswear made of polyester $(\mathrm{P}<0.05)$. Clothing fit only had significant effect on conductive heat loss; that is tight-fit sportswear showed greater conductive heat loss than loose-fit one $(\mathrm{P}<0.05)$. Regarding subjective responses, participants reported lower thermal comfort, greater thermal sensation, and greater skin wetness sensation when performing exercise wearing tight-fit sportswear made of polyester.
\end{abstract}

\section{Introduction}

In 2012, sales of sportswear in global markets exceeded \$ 244 billion [1]. The sale included 46 countries around the world who estimated that sales of clothing and sports shoes would grow more than $7.5 \%$ in 2012 and continued to increase until 2017 with additional sales of $\$ 55$ billion. This increasing demand should be balanced with ergonomic sportswear design in an attempt to optimize an athlete's performance.

Sportswear is generally designed with a certain level of clothing fit to give freedom of movement. The level of clothing fit plays an important role in providing freedom of movement and comfort [2]. The loose-fit sportswear generally has a larger shirt size thus it widens the distance between the skin and the shirt that facilitating the occurrence of air circulation and heat release through convection. Therefore, wearing loose-fit clothing may decrease physiological strain during exercise through convective heat lose [3]. However, loose-fit sportswear can block sweat evaporation as a result of an increase of thermal insulation [4]

In addition to the clothing fit, the clothing material of a sportswear also plays important role. Sportswear made of fabric that has large fibber pores will tend to easily release heat through the pores [5]. Cotton fabric has a characteristic to absorb sweat, wool has the characteristic to regulate body temperature in all conditions (hot or cold) but not suitable for sportswear because this type of cloth is not light. Silk has a very compact characteristic but it is expensive. polyester (spandex) has a flexible characteristic that follows body shape so that it can move freely, and so on [2]. Among these fabrics, cotton and polyester are commonly used as clothing material for sportswear. In comparison with cotton, exercise wearing the polyester produced a greater sweating efficiency and less clothing regain. However, thermo-physiological and subjective sensations during the intermittent highintensity exercise were similar for both fabrics. In addition, the thermal and rating of shivering/sweating sensation were lower after exercise in the warm and humid environment in subjects wearing polyester than when wearing cotton fabric [6]. Based on this explanation, the selection of material types highly contributes to the comfort of its wearer during exercise.

There has been a less number of study on encapsulated women's clothing, especially for Islamic sportswear. Al Ajmi et al. [7] may be the first who measured the value of thermal insulation of clothing (Clo) of some of the commonly used clothing in the Arabian Gulf region. However, they did not include the investigation of thermo-physiological effect of the clothing. A study by

\footnotetext{
* Corresponding author: twijaya@ugm.ac.id; astrid.w.adventri@gmail.com
} 
Davis et al. [8] investigated the effects of women Islamic sportswear that encapsulated subjects whole body except hands and face on physiological responses. They reported that subjects felt thermally discomfort when wearing the Islamic sportswear, but they did not find any significant different in physiological responses and dehydration level in comparison with traditional soccer outfit. Another study by Wijayanto et al. [3] compared tight-fit and loosefit Islamic sportswear made of polyester worn during exercise. They found that wearing tight-fit sportswear resulted in greater thermal strain than wearing the loosefit one [3].

Thus far, there were no study investigating the clothing material for sportswear, especially for sportswear that encapsulate whole body except face and hands. From the aforementioned, this study investigated the effect of clothing fit and material used in encapsulated women's sportswear on physiological and subjective response during exercise in hot and humid environment.

\section{Methods}

\subsection{Participants}

Twelve healthy females with a mean $( \pm$ SD) age of 20.3 years $( \pm 0.4)$, body mass of $52.7 \mathrm{~kg}( \pm 0.95)$, height of 1.59 $\mathrm{m}( \pm 1.9)$, and body surface are of $1.53 \mathrm{~m}^{2}( \pm 0.02)$ participated in this study. They were not pregnant or not in their menstruation period during the experiment period. Prior to participation, the details and risks associated with the experiment protocol were explained. Written informed consent was obtained in accordance with the local institutional review board policy for use of human subjects.

\subsection{Clothing Ensemble}

Four types of Islamic sportswear for female comprised of two level of clothing fit: loose-fit and tight-fit, and two types of material for sportswear: cotton and polyester were selected for the main experiment. The garments covered and encapsulate the entire participant's body, except face and hands.

The tight-fit garment was designed with the clothing tightly fit to the participant's body (air gap between the skin and garment was less than $10 \mathrm{~mm}$ ) and head cover prepared to cover and compressed the head and the neck. The loose-fit garment was designed with the gap between the skin and garment was between 14 and $21 \mathrm{~mm}$ and head cover prepared to cover head, neck, and chest with compression on the head only, so as not to outline the shape of the body. These sportswears were made of two types of material: one made of $93 \%$ polyester and $7 \%$ elastin (PES), the other of $100 \%$ cotton fabric (CT). The clothing ensembles in this study are shown in Figure 1.

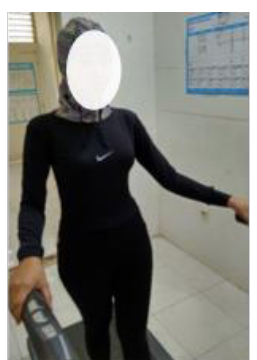

(a)

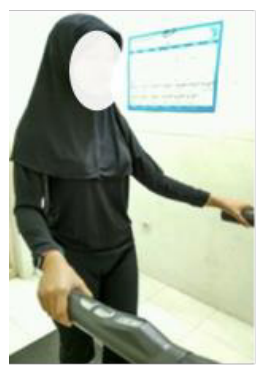

(c)

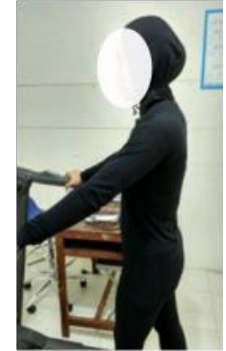

(b)

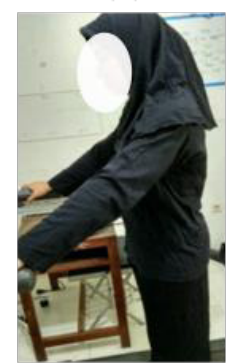

(d)
Fig. 1. (a) Clothing ensemble for tight-fit polyester, (b) tight-fit cotton, (c) loose-fit polyester, (d) loose-fit cotton.

\subsection{Measurements}

Tympanic temperature $\left(\mathrm{T}_{\mathrm{ty}}\right)$ was monitored every second using an infrared tympanic temperature sensor (CE Thermo, Nipro Corporation, JAPAN). The $\mathrm{T}_{\text {ty }}$ probe was gently introduced into the ear canal, so that the probe correctly positioned towards the tympanic membrane. Then the outer ear was cover throughout the whole exposure.

Body heat balance was estimated from heat gain and heat loss at the end of exercise. Heat gain was calculated as external work subtracted from metabolic heat production $(\mathrm{M}-\mathrm{W})$, whereas heat loss was estimated from conductive heat loss $\left(\mathrm{K}_{\mathrm{sk}}\right)$, sensible heat loss $(\mathrm{C}+\mathrm{R})$, and evaporative heat loss $\left(E_{\mathrm{sk}}\right)$. Body heat storage $(\mathrm{S})$ was estimated from the product of the body mass (BM), human body specific heat ( $\left.\mathrm{c}_{\text {body }}\right)$ and the rate of increase in mean body temperature $\left(\Delta T_{\text {body }} \cdot \Delta t^{-1}\right)$ from the baseline to the end of exercise $\left(\mathrm{S}=\mathrm{BM} \cdot \mathrm{c}_{\text {body }} \cdot \Delta T_{\text {body }} \cdot \Delta t^{-1}\right)$.

For subjective thermal measurements, each participant gave a verbal evaluation of their thermal condition using nine points rating thermal sensation (TSV, 4 : very hot, 3 : hot, 2: warm, 1: slightly warm, 0 : neither, -1 : slightly cool, -2: cool, -3 : cold, and -4 : very cold), seven points of thermal comfort (TCV, 3: very comfortable, 2: comfortable, 1: slightly comfortable, 0 : neither, -1: slightly uncomfortable, -2 : uncomfortable, and -3 : very uncomfortable), Rating of Perceived Exertion (RPE) based on Borg's scale, and skin wetness sensation (SW) [9] every 10-min.

\subsection{Data analysis}

Data are presented in mean \pm standard deviation (SD). Prior to the main statistical analysis, data were tested for 
normal distribution using the Kolmogorov-Smirnov test, and all scale data were normally distributed. Data from time-course measurements were evaluated using a repeated measure analysis of variance (RM ANOVA). Multiple paired comparison with Bonferroni correction was used to determine to determine significant difference between conditions. The nonparametric Wilcoxon signedrank test was performed to compare the changes in subjective ratings of perceptions (TSV, TCV, RPE, and $\mathrm{SW})$. Significant level was established at $\mathrm{P}<0.05$.

\section{Results}

\subsection{Tympanic Temperature}

Figure 2 depicts the changes in $\mathrm{T}_{\mathrm{ty}}\left(\Delta \mathrm{T}_{\mathrm{ty}}\right)$ at rest, during exercise and recovery when the participants wore tight-fit polyester, loose-fit polyester, tight-fit cotton, and loose-fit cotton. $\Delta \mathrm{T}_{\text {ty }}$ was significantly higher in comparison between tight-fit cotton compared to the and tight-fit polyester condition $(\mathrm{P}<0.05)$ and was also significantly higher in comparison between loose-fit polyester compared to the tight polyester condition at the end of exercise $(\mathrm{P}<0.05)$. During the recovery period, $\Delta \mathrm{T}_{\text {ty }}$ was significantly higher for the tight cotton compared to the tight polyester condition, significantly higher for the loose polyester compared to the tight polyester condition, and also significantly higher for the loose cotton compared to the tight polyester condition $(\mathrm{P}<0.05)$.

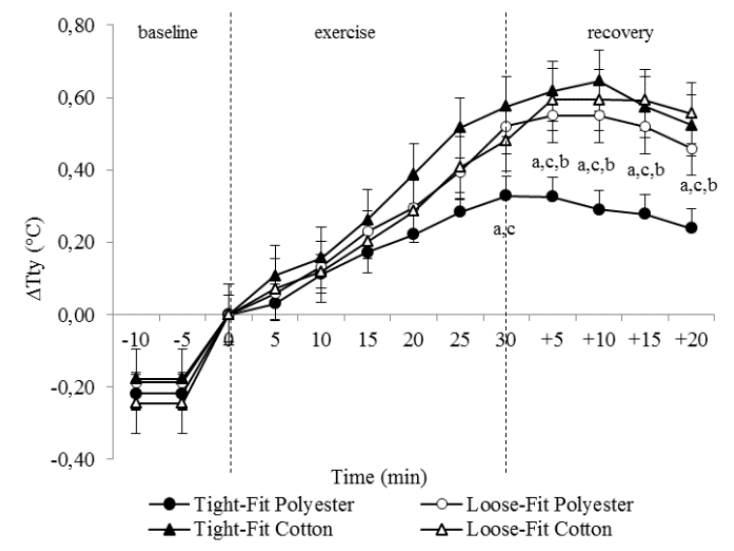

Fig. 2. Change of tympanic temperature $\left(\Delta \mathrm{T}_{\mathrm{ty}}\right)$ during baseline, exercise, and recovery. ${ }^{a}$ shows significant between tight-fit polyester and tight-fit cotton at $\mathrm{P}<0.05$; ${ }^{\mathrm{b}}$ shows significant between tight-fit polyester and loose-fit cotton at $\mathrm{P}<0.05$; ${ }^{\mathrm{c}}$ shows significant between tight-fit polyester and loose-fit polyester at $\mathrm{P}<0.05$.

\subsection{Thermal Balance}

Table 1 shows body heat balance at the end of exercise phase. $E_{\mathrm{sk}}$ was significantly higher when wearing polyester, either tight-fit or loose-fit, than when wearing tight-fit cotton during exercise $(\mathrm{P}<0.05) . \quad \mathrm{K}_{\text {sk }}$ was significantly higher when wearing tight-fit garment than when wearing loose-fit garment during exercise $(\mathrm{P}<0.05)$. Sensible heat loss $(\mathrm{C}+\mathrm{R})$ was significantly higher when wearing tight-fit cotton than when wearing loose-fit cotton $(\mathrm{P}<0.05)$. There were no significant differences in $\mathrm{M}-\mathrm{W}$ and $\mathrm{S}$ among conditions at the end of exercise.

Table 1. Body heat balance at the end of exercise (mean \pm SD)

\begin{tabular}{|l|l|l|l|l|}
\hline & \multicolumn{2}{|c|}{ Tight-fit } & \multicolumn{2}{c|}{ Loose-fit } \\
\hline & Polyester & Cotton & Polyester & Cotton \\
\hline $\mathrm{M}-\mathrm{W}\left(\mathrm{Wm}^{-2}\right)$ & $150.6 \pm 18.1$ & $127.7 \pm 22.1$ & $154.7 \pm 20.8$ & $145.6 \pm 24.4$ \\
\hline $\mathrm{E}_{\text {sk }}\left(\mathrm{Wm}^{-2}\right)$ & $60.5 \pm 1.9^{\mathrm{c}, \mathrm{d}}$ & $19.6 \pm 0.4^{\mathrm{d}}$ & $59.6 \pm 1.7^{\mathrm{c}, \mathrm{d}}$ & $18.3 \pm 0.5$ \\
\hline $\mathrm{K}_{\text {sk }}\left(\mathrm{Wm}^{-2}\right)$ & $36.9 \pm 4.6^{\mathrm{b}, \mathrm{c}, \mathrm{d}}$ & $19.9 \pm 3.8^{\mathrm{d}}$ & $2.3 \pm 0.4^{\mathrm{c}}$ & $1.6 \pm 0.2$ \\
\hline $\mathrm{C}+\mathrm{R}\left(\mathrm{Wm}^{-2}\right)$ & $15.7 \pm 1.6$ & $18.3 \pm 1.7^{\mathrm{d}}$ & $14.5 \pm 1.2$ & $14.3 \pm 1.3$ \\
\hline $\mathrm{S}\left(\mathrm{Wm}^{-2}\right)$ & $123.2 \pm 15.8$ & $152.8 \pm 17.5$ & $140.5 \pm 15.7$ & $147.9 \pm 14.1$ \\
\hline
\end{tabular} $\begin{aligned} & \mathrm{a}=\text { significantly different to tight-fit polyester at } \mathrm{P}<0.05 \\
& \mathrm{~b}=\text { significantly different to loose-fit polyester at } \mathrm{P}<0.05 \\
& \mathrm{c}=\text { significantly different to tight-fit cotton at } \mathrm{P}<0.05 \\
& \mathrm{~d}=\text { significantly different to loose-fit cotton at } \mathrm{P}<0.05\end{aligned}$

\subsection{Subjective Responses}

Table 2 depicts the subjective responses during exercise. Participants reported greater thermal discomfort (TCV) during exercise in tight-fit polyester than in loose-fit polyester $(\mathrm{P}<0.05)$. Thermal sensations $(\mathrm{TSV})$ were significantly warmer when wearing tight-fit polyester than when wearing loose-fit polyester or tight-fit cotton garment during exercise $(\mathrm{P}<0.05)$.

Perceived exertion during exercise was significantly harder when wearing tight-fit polyester than when wearing tight-fit cotton $(\mathrm{P}<0.05)$ and was also harder when wearing tight-fit cotton than when wearing loose-fit cotton $(\mathrm{P}<0.05)$. Finally, skin wetness sensation ( $\mathrm{SW})$ was greater in tight-fit polyester than when wearing tightfit cotton garments during recovery $(\mathrm{P}<0.05)$. Skin wetness was sensed to be significantly worse when wearing tight polyester garment than when wearing loose polyester or loose cotton garment during exercise $(\mathrm{P}<0.05)$.

Table 2. Subjective responses (mean \pm SD)

\begin{tabular}{|l|l|l|l|l|}
\hline \multirow{2}{*}{} & \multicolumn{2}{|c|}{ Tight-fit } & \multicolumn{2}{c|}{ Loose-fit } \\
\cline { 2 - 5 } & \multicolumn{1}{|c|}{ Polyester } & \multicolumn{1}{c|}{ Cotton } & \multicolumn{1}{c|}{ Polyester } & \multicolumn{1}{c|}{ Cotton } \\
\hline TCV & $-2 \pm 0.3^{\mathrm{b}}$ & $-1 \pm 0.4$ & $-1 \pm 0.4$ & $-1 \pm 0.4$ \\
\hline TSV & $3 \pm 0.3^{\mathrm{c}, \mathrm{b}}$ & $2 \pm 0.3$ & $2 \pm 0.3$ & $3 \pm 0.2$ \\
\hline RPE & $12 \pm 0.8^{\mathrm{c}, \mathrm{d}}$ & $11 \pm 0.7$ & $12 \pm 0.7^{\mathrm{d}}$ & $11 \pm 0.8$ \\
\hline SW & $76.6 \pm 6.7^{\mathrm{b}, \mathrm{d}}$ & $72.4 \pm 7.5$ & $63.4 \pm 7.9$ & $69.3 \pm 7.5$ \\
\hline
\end{tabular}

$\mathrm{a}=$ significantly different to tight-fit polyester at $\mathrm{P}<0.05$

$\mathrm{b}=$ significantly different to loose-fit polyester at $\mathrm{P}<0.05$

$\mathrm{c}=$ significantly different to tight-fit cotton at $\mathrm{P}<0.05$

$\mathrm{d}=$ significantly different to loose-fit cotton at $\mathrm{P}<0.05$

\section{Discussion}

Wearing Islamic Sportswear made of cotton resulted in a higher increase of tympanic temperature during exercise than wearing the other made of polyester. This may be due to water-transfer properties of polyester. The water 
permeability of polyester $(528.1 \mathrm{~mm} / \mathrm{s})$ is higher than cotton $(327.1 \mathrm{~mm} / \mathrm{s})$. Thus, polyester absorbs less sweat but spread and evaporate sweat faster than cotton [6]. Evaporative heat loss when using polyester fabric is higher than when using cotton fabric. It is possible that higher evaporative heat loss when wearing polyester fabric released heat from within the body more rapidly. As a result, a smaller increase of tympanic temperature was observed when wearing polyester fabric during exercise in comparison with other of cotton.

In this study, thermal sensation, thermal comfort, and skin wetness were significantly higher when wearing tight-fit garment, in comparison with loose-fit garment. These findings were in agreement to [3]; wearing tight-fit garment were sensed to be hotter and produced more thermal discomfort compared to wearing the loose-fit one. Wearing tight-fit clothing was reported to be uncomfortable because direct contact between the fabric and the skin. There were some evidences that thermal sensation and clothing sensation are associated with skin wetness $[10,11]$. The more widely moisture is distributed over the skin, the stronger the discomfort sensation [12, 13]. In the present study, the participants reported higher thermal sensation, greater thermal discomfort, and more wetness sensation when wearing the tight-fit than the loose-fit clothing. A study suggested that increase contact of the skin with the clothing in tight-fit clothing increase dampness and lead to negative impact of thermal comfort [12]. In addition, more sensation of skin wetness would affect the weight of the garment, impair heat dissipation from the skin, and post-exercise impairment evaporative cooling $[14,15]$. Compared with exercise wearing the cotton, exercise wearing the polyester fabric produced a greater sweating efficiency and less clothing regain (i.e., less sweat retention), but subjective sensations during the intermittent high-intensity exercise were similar for both fabrics [6].

\section{Conclusion}

In conclusion, our findings suggest tight-fit Islamic sportswear for women that made from polyester had no detrimental effects on physiological responses and had less body heat storage during performing moderate exercise in hot environment. However, it should be considered that wearing tight-fit sportswear that encapsulates whole body except hands and face may produce greater thermal discomfort during exercise. Further studies investigating the relationship between physiological indices and subjective responses during exercise wearing this type of sportswear is necessary to gain more insight in designing Islamic sportswear for women.

\section{References}

1. R. Shishoo, Introduction to textiles in sport, Textile for sportswear (Woodhead Publishing, Sweden, 2015)

2. J. McCann, Environmentally conscious fabric selection in sportswear design, Textile for sportswear (Woodhead Publishing, United Kingdom, 2015)

3. T. Wijayanto, M.F. Fathna, Y. Tochihara, Physiological responses during exercise wearing women's islamic sportwear in warm humid environment, The fifth international conference on human-environment system (2016)

4. Y.S. Chen, J. Fan, X. Qian, W. Zhang, Effect on garment fit on thermal insulation and evaporative resistance, Textile research journal, 74, 742 (2004)

5. R.M. Rossi, Cold weather sports clothing, Textile for sportswear (Woodhead Publishing, Switzerland, 2015)

6. M. Brazaitis, S. Kamandulis, A. Skurvydas, G. Havenith, The effect of two kinds of t-shirt on physiological and psychological thermal responses during exercise and recovery, Applied ergiomic, 42, 46 (2010)

7. F.F. Al-ajmi, D.L. Loveday, K.H. Bedwell, G. Havenith, Thermal insulation and clothing area factors of typical Arabian gulf clothing ensembles for males and females: measurements using thermal manikins, Applied ergonomics, 39, 407 (2008)

8. J.K. Davis, P.A. Bishop, Y. Zhang, J.M. Green, C. Casaru, K.D. Orrick, M.C. Smith, M.T. Richardson, R.E. Schumacker, Fluid balance, thermal stress, Nd post exercise response in women's islamic athletic clothing, European journal of applied physiology, 112, 725 (2012)

9. J.Y. Lee, K. Nakao, Y. Tochihara, Validity of perceived skin wettedness mapping to evaluate heat strain, Eur j appl physiol, 111, 2581 (2011)

10. D.D. Pascoe, T.A. Bellingar, B.S. McCluskey, Clothing and exercise: II. Influence of clothing, during exercise/work in environment extremes, Sports med, 18, 94 (1994)

11. Y. Aoyagi, T.M. McLellan, R.J. Shephard, Effects of endurance training and heat acclimation on psychological strain in exercise men wearing protective clothing, Ergonomics, 41, 328 (1998)

12. A.R. Gwosdow, J.C. Berglund, J.A.J. Stolwijck, Skin friction and fabric sensation in neutral and warm environment, Textile res. $j$, 56, 754 (1986)

13. D.M. Scheurell, S.M. Spivak, N.R.S. Hollies, Dynamic surface wetness of fabric in relation to clothing comfort, Textile res. j, 55, 392 (1985)

14. T.P. Gavis, Clothing and thermoregulation during exercise, Sports med, 33, 941 (2003)

15. X.Q. Dai, R. Imamura, G.L. Liu, F.P. Zhou, Effect of moisture transport on microclimate under t-shirt, Eur j. appl physiol, 104, 337 (2008) 